\title{
MORAL, ÉTICA E ESTÉTICA DA EXISTÊNCIA EM MICHEL FOUCAULT
}

\author{
Miguel Ângelo Oliveira do Carmo ${ }^{1}$ \\ Universidade Federal da Paraíba (UFPB) \\ (i) https://orcid.org/0000-0002-4793-325X \\ E-mail:mguel@hotmail.com
}

\section{RESUMO:}

O presente texto tem como objetivo não só precisar os conceitos de "moral", "ética" e "estética da existência", nos períodos estudados por Michel Foucault, como também captar suas diferenças significativas, tendo em vista o direcionamento para a possibilidade de uma ético-política na e da atualidade. Tais estudos arqueo-genealógicos da Grécia Clássica (século IV A.C.), do período GrecoRomano (séculos I-II D.C.) e do Cristianismo (séculos III-IV D.C.), mostram que os referidos conceitos mantem sua marca, de época em época, pela utilização de técnicas que visavam atingir a temperança e um cuidado de si cada vez maior e detalhado. A estilização da vida ganhou formas das mais variadas neste processo histórico, tendo como base práticas que, por vezes, aproximavam ou não a atitude moral da atitude ética. Essa flexibilidade dos usos dos conceitos, consequentemente, das práticas históricas e culturais, traz em Foucault a abertura do pensamento na busca de uma atitude política perante os atos, os pensamentos e a liberdade.

PALAVRAS-CHAVE: Moral; Ética; Estética da Existência; Michel Foucault.

\section{MORAL, ETHICS AND AESTHETICS OF THE EXISTENCE IN MICHEL FOUCAULT}

\begin{abstract}
:
The present text has as objective not only to define the concepts of "moral", "ethics" and "aesthetics of existence", in the periods studied by Michel Foucault, but also to capture their significant differences, in view of the orientation towards the possibility of an ethical-political in and of the present time. Such arche-genealogical studies of Classical Greece (4th century BC), of the GrecoRoman period (1st and 2nd century AD) and of Christianity (3rd and 4th centuries AD), show that these concepts maintain their mark, by the use of techniques aimed at achieving temperance and an increasing and detailed care of itself. The stylization of life gained forms of the most varied in this historical process, based on practices that sometimes approached the moral attitude of the ethical attitude. This flexibility of the uses of concepts, consequently of historical and cultural practices, brings in Foucault the opening of thought in the search for a political attitude towards acts, thoughts and freedom.
\end{abstract}

KEY WORDS: Moral; Ethic; Aesthetics of Existence; Michel Foucault.

\footnotetext{
1 Doutor em Filosofia pela Universidade Federal do Rio de Janeiro (UFRJ), Rio de Janeiro - RJ, Brasil. Professor Associado da Universidade Federal da Paraíba (UFPB), João Pessoa - PB, Brasil.
} 
No segundo momento do projeto foucaultiano História da Sexualidade, O Uso dos Prazeres (1984) e O Cuidado de Si (1985) e em um conjunto de entrevistas, artigos e conferências espalhados no Dits et Écrits (principalmente o terceiro e quatro volumes), vemos perfilar não só um estudo do homem como sujeito do desejo, mas também o estabelecimento dos conceitos de "moral", "ética" e "estética da existência". A tentativa de tomar tais conceitos, em Foucault, nos traz grandes dificuldades, pois, ao mesmo tempo em que se relacionam teoricamente, deixam evidenciar um caráter histórico e prático inovador na análise dos mesmos. Dito isto, a questão que se apresenta é: quais os limites de aproximação e/ou distância na relação entre esses conceitos e para onde eles, ou a relação entre eles, finalmente apontam? Nos estudos empreendidos sobre a sexualidade, a problematização éticoerótica dos gregos, no século IV A.C., e a destacada "cultura de si", tão eminente nos primeiros séculos de nossa era, podem nos mostrar como caminha tal relação. O que pretendemos é mostrar formas culturais de grande importância para Foucault que, com certa sintonia, moldaram modos de vida trazendo outros significados na relação entre ética, estética e moral.

Os gregos, no seu fazer ético e moral, no seu modo de viver, questionaram a verdade e também outros elementos nos quais a procura de uma estilização da vida encontrava dificuldades diante das práticas sexuais. A moral grega, aquela elaborada por homens e mulheres no seu dia a dia, direcionava-se apenas para homens e tomava sempre um formato "viril"; nesta, a mulher aparece ou a título de objeto ou como parceiras às quais convém educar e vigiar, se estiver sobre o poder do homem, ou ainda tinham de se abster, quando sobre outro domínio (pai, tutor, etc.). Esta prática procurou não "definir um campo de conduta e um domínio de regras válidas" para todos; não que a interdição não existisse e pesasse sobre todos, nem que uma normalização não estivesse sempre atuando, mas que era necessário, com a autoridade, poder e liberdade própria ao indivíduo, praticar os prazeres que não fossem condenáveis e, ao mesmo tempo, com certa austeridade. Tudo isso se dava através de "eixos" temáticos como a Dietética, a Econômica e a Erótica, temas profundamente analisados por Foucault. "É preciso compreender esses temas da austeridade sexual não como uma tradição ou um comentário de proibições profundas e essenciais, mas como elaboração e estilização de uma atividade no exercício de seu poder e na prática de sua liberdade" (FOUCAULT, 1994c, p. 554).

É preciso compreender também que a cada tema correspondem várias relações concretas, ou seja, na Dietética, temos as relações com o corpo, com a saúde e todo um jogo de vida e de morte que está por trás ou relacionadas a essas práticas; na Econômica, relações com o outro sexo, com a esposa como parceira privilegiada, relações que se dão no jogo entre a instituição familiar e o vínculo criado por ela; na Erótica, relação com o seu próprio sexo, com a difícil questão dos parceiros a escolher e com o problema do ajustamento entre papéis sociais e sexuais; e, por fim, na relação com a verdade, que dará as condições espirituais que permitam ter acesso à sabedoria (FOUCAULT, 1994c, p. 554). Portanto, temos de um lado uma liberdade no uso das regras e, por outro, uma imposição de regras no uso da liberdade - eis o caráter paradoxal praticado pela moral do homem grego.

Nesta prática cultural, própria do helenismo clássico e greco-romano, quando a liberdade se colocava em realização, em processo de estilização da vida, a mesma 
acabava sendo objeto de problematização intensa, principalmente na prática sexual. Como contrabalançar essa abertura nas ações e, ao mesmo tempo, manter certo limite nessas ações? Como ser livre diante da lei sem feri-la? Por que esta problematização pesava sobre esta cultura? Buscando entender tal problema, Foucault delimitará o conceito de ética, em relação constante com uma estética da vida, contrapondo-o com o de moral. Irá, ainda, em sua análise, estruturá-lo basicamente em quatro pilares fundamentais. Vejamos, pois, a apresentação de tais conceitos, tentando mostrar que quando se faz referência a uma ética se faz, também, a uma moral que terá seu sentido na prática da ou para a liberdade. Veremos que esta ética, na colocação de uma relação do indivíduo consigo mesmo, ainda que atrelado a regras morais, pode transbordar para uma estética da existência, na qual o estilo de viver pode ganhar qualquer forma, qualquer contorno, sem burlar o código prescrito. "Derivação" e "descolamento", dirá Deleuze, sobre a novidade apresentada pelos gregos $(2006$, p. 107) e que Foucault percebeu muito bem ao emparedar moral e ética.

\section{Moral e ética}

No ensaio introdutório Usage des Plaisirs et techniques de Soi, a definição da palavra moral é colocada em um duplo sentido, o que nos mostra a tentativa de pensar tal conceito dentro de uma mobilidade histórica: primeiro, aparece como um "conjunto de regras e valores" proposto aos indivíduos por aparelhos prescritivos como família, igreja, instituições educativas, etc.; depois, como um "comportamento real" dos indivíduos em relação às regras e valores propostos. Quanto a esta moral, nos encontramos no âmbito da "moralité des comportements"; quanto àquela, prescritiva, estamos no nível do "code moral". Temos, então, um movimento duplo e intrinsicamente contrário aqui: de um lado, a moral como regras para condutas e, de outro, como condutas possíveis em relação à(s) regra(s). Já em relação a ética, que também recebe um caráter histórico, aparece como o "conduzir-se", isto é, de que maneira posso e devo constituir-me como sujeito moral? De que modo devo agir perante a mim mesmo para aceder a uma posição ética verdadeira? O elemento do autogoverno passa a reger o trabalho moral (FOUCAULT, 1994c, pp. 555-556). Numa entrevista a P. Rabinow e H. Dreyfus, Foucault desdobra tudo isso:

Penso que, em uma história da moral, é preciso fazer uma distinção entre o código moral e os atos. Os atos ou as condutas são a atitude real dos indivíduos face às prescrições morais que lhe são impostas. Nestes, deve-se distinguir o código que determina quais atos são autorizados ou proibidos e qual o valor positivo ou negativo das diferentes atitudes possíveis. Mais há outro aspecto das prescrições morais que, geralmente, não é isolado como tal, mas que, aparentemente, é muito importante: é a relação consigo mesmo que seria necessário instaurar, relação a si (rapport à soi) que determina como o indivíduo deve constituir-se como sujeito moral de suas próprias ações (FOUCAULT, 1994f, p. 618).

Este relato mostra que, ao mesmo tempo em que comparece uma diferenciação, é transparente a fronteira que distingue a moral, em seu sentido ambíguo, e a ética foucaultianas. É como uma inseparabilidade dos conceitos: ser moral, estar 
praticando ações valorativas, exemplares e em conformidade com a lei, é, também, ser ético, é estar praticando uma ação moral consigo próprio como auto constituição. Ou seja, há um elemento da prática moral que alimenta diretamente a prática ética; ao contrário, há uma face ética, dobra do próprio indivíduo, presente nos atos morais. Assim, "A ação moral é indissociável dessas formas de atividade sobre si, que não são menos diferentes de uma moral para outra do que o sistema de valores, de regras e de proibições" (FOUCAULT, 1994c, p. 558). A ética aparece como uma prática moral: a da relação do indivíduo consigo mesmo, da constituição modelar das subjetivações, portanto, nem moral dos comportamentos nem moral ligada estritamente ao código, mas moral do fazer-se contínuo em acontecimentos.

Se este fazer-se ético é histórico, pois é um tipo de moral, ele se dá de várias formas, de vários modos. A esta variação, Foucault liga quatro aspectos (ou estruturas) para análise da sua "ética": a determinação da substância ética, o modo de sujeição, o trabalho ético e a teleologia. O primeiro é a maneira pela qual o indivíduo constitui tal parte dele mesmo como matéria de sua conduta moral, é a matéria a ser ocupada pela ética e que muda na história. Para os gregos, a substância era a aphrodisia, "os atos de Afrodite" — amar alguém e não tocá-lo era um ato valorizado. Já na era cristã, o problema não era mais como atuar perante o prazer e o desejo, e, sim, que tipo de desejo deveria se ter na atividade sexual.

O modo de sujeição aparece como o modo pelo qual o indivíduo se relaciona com a regra moral e se reconhece como ligado à obrigação de praticá-la. Se pratico a fidelidade conjugal e me submeto à regra, ou é porque faço parte de uma cultura ou de um grupo que a aceita e a conserva, ou porque sigo uma certa tradição, ou ainda, porque luto comigo para me impor uma nova forma de viver. G. Deleuze mostra que este modo de sujeição é duplo: a submissão ao outro, que se dá pela supremacia do código, e a submissão a si, o afeto de cada um a sua identidade própria, pela consciência e conhecimento que se tem de si — de um lado, a sujeição ao outro; de outro, a sujeição a si (1987, pp. 138-139).

A terceira estrutura, o trabalho ético, é toda prática de si efetuada no sentido de não só dar conformidade entre um comportamento e uma regra, mas também de modificar a si próprio, em direção a um ser moral de sua própria conduta. Se procuro a fidelidade conjugal, devo realizar uma vigilância constante sobre meus desejos, meus atos; devo assimilar bem as "regras" da fidelidade e aplicá-las com exatidão; enfim, me transformar junto a minha conduta moral.

Quarta estrutura: a teleologia. Aqui, encontramos o fim "último" do trabalho ético, ou seja, a procura do ser ao qual aspiramos ao nos sujeitarmos diante da moral. Queremos "nos tornar puros, ou imortais, ou livres, ou mestres de nós mesmos"?

São estes "modos de subjetivação" que na história, passando pela Antiguidade tardia e pela era primitiva cristã, adquiriram várias formas. Nos séculos I e II D.C., surgiu uma cultura na qual toda e qualquer problematização recaiu sobre o cuidarse; o cuidado de si, epimeleia heauton, foi cada vez mais forte e tornou-se um certo modo de vida. Esse modo de vida recaia sobre o próprio indivíduo exigindo dele um trato para consigo cada vez amis determinado e eficiente. A forma do belo modo de existir arremessava todos a um destino que só se realizava pelo trabalho incansável sobre si mesmo. Nessa cultura

CARMO, Miguel Ângelo Oliveira do. Moral, ética e estética da existência em Michel Foucault. Griot : Revista de Filosofia, Amargosa - BA, v.19, n.2, p.300-310, junho, 2019. 
- mais do que novas interdições sobre os atos — é a insistência sobre a atenção que convém ter para consigo mesmo; é a modalidade, a amplitude, a permanência, a exatidão da vigilância que é solicitada; é a inquietação com todos os distúrbios do corpo e da alma que é preciso evitar por meio de um regime austero; [enfim,] é a importância de se respeitar a si mesmo, não simplesmente em seu próprio status, mas em seu próprio ser racional, suportando a privação dos prazeres ou limitando o seu uso ao casamento ou à procriação (FOUCAULT, 1985, pp. 46-47).

No cristianismo, a substância passa a ser o desejo; a teleologia, a pureza, a imortalidade; no ascetismo, o autoexame toma a forma de autodecifração; e o modo de sujeição passa a ser a lei divina. Vemos, então, que a ética, com as suas estruturas, não foi sempre a mesma de época em época. E nem poderia ser, pois "A liberdade é a condição ontológica da ética. Mas a ética é a forma refletida que toma a liberdade" (FOUCAULT, 1994g, p. 712), ou seja, um conjunto de problematizações a serem refletidas em seu caráter histórico-ontológico, em sua possibilidade de liberdade.

Se a ação moral se cumpre em sua própria realização, nesta o indivíduo não deixa de se ligar ao código; mas também não deixa, de certo modo, de relacionar-se. A "ética" é um jogo complexo de proximidades e afastamentos entre uma ação moral, um código e um constituir-se, praticar uma ação moral, procurar respeitar uma lei e dar-se em construção contínua em uma modelação da alma são três instâncias que, ao longo da vida, devem se ajustar uma à outra; é uma "dobra ontológica", uma "dobra do ser", é a dobra da ética numa estética da existência.

\section{Estética da existência}

Temos então uma transposição de uma genealogia do poder para uma estética da existência ancorada em uma busca de autonomia. Nessas pesquisas, Foucault tenta ultrapassar a concepção das relações de poder como relação entre forças complexas, estratégicas, e que grassam em plena liberdade, pois esta é a condição principal para a existência daquelas ${ }^{2}$. Essa ultrapassagem do conhecido modelo de guerra nietzschiano para uma ética e estética da existência não deixou de ser alimentada por uma problemática que, inicialmente, encontrou guarida nas questões da conduta e depois se expressou pelo tema da verdade, ou melhor, do dizer verdadeiro. Mas fiquemos incialmente com sua relação com Kant.

Com o estudo do texto kantiano Was ist Aufklãrung?, de 1784, percebeu-se a importância da questão e da sua remissão à constante atualização do indivíduo no seu tempo - bom uso da razão no diagnóstico do presente contra toda forma de poder individualizante. Com o poder microfisicamente disseminado na vida, com a sua intensa e limitada margem de criação, era preciso conjugar determinadas imposições de resistência aos poderes dominantes. Em um cenário de absoluta administração da vida, conclui-se

\footnotetext{
${ }^{2}$ Eis um dos pontos fundamentais da sua analítica do poder: a afirmação de que a liberdade não se reveste de posições ideológicas e transcendentais, ou seja, ser livre é estar enredado nas complexas relações de poder — e tais relações só terão sentido nas suas livres realizações. De saída, não podemos pensar uma contradição entre poder e liberdade, mas um jogo definidor entre eles, pois o poder só é exercido sobre "sujeitos livres".
}

CARMO, Miguel Ângelo Oliveira do. Moral, ética e estética da existência em Michel Foucault. Griot : Revista de Filosofia, Amargosa - BA, v.19, n.2, p.300-310, junho, 2019. 
que o problema ao mesmo tempo político, ético, social e filosófico que se coloca para nós hoje não é o de experimentar liberar o indivíduo do Estado e suas instituições, mas o de nos liberar nós mesmos do Estado e do tipo de individualização que a ele se liga. Precisamos promover novas formas de subjetividade recusando o tipo de individualidade que nos impuseram durante vários séculos (FOUCAULT, 1994b, p. 232).

Tentativa de limitação de uma objetivação do sujeito, incrementada pelas tecnologias de poder que perpassam todo o tecido social, para ir ao encontro de formas, de novas ambiências, novos processos de subjetivação. É na relação de uma força consigo mesma que o homem desprende-se de si e é lançado a possibilidades vivenciais inesperadas. A cultura de si grega viveu essas experiências e enfrentou um novo mundo marcado por terrenos mais artísticos. Essas "artes da existência" nada mais são que

\footnotetext{
práticas refletidas e voluntárias pelas quais os homens não somente se fixam regras de conduta, mas também buscam se transformar, se modificar em seu ser singular, e fazer de sua vida uma obra que porte certos valores estéticos e responda a certos critérios de estilo (FOUCAULT, 1994c, p. 545).
}

Os gregos dobravam-se, estilizaram-se, e por isso tinham uma technè da vida. Por exemplo, toda preocupação, na prática sexual, com a atividade-passividade e a austeridade que se tinha, fizera-os embelezar a vida traçando certos critérios para essa prática. A estética da existência grega estava ancorada na austeridade, em uma severidade para a realização de técnicas que proporcionavam um bom uso do prazer. Aqui é preciso observar: a realização do prazer em torno desta severidade não visava o prazer pelo prazer, mas o bom uso desse prazer diante dos problemas que o mesmo comportava: não amar qualquer um, ter certo limite no dispêndio do sêmen, manter certo status na relação, etc.

No estudo do período greco-romano, vemos que esta estética realizou-se, com grande importância, no "cuidado de si"; toda uma cultura de si onde as técnicas da vida (technè tou bioù) se ancoraram na relação de si para si. Foi como se o grande ensinamento socrático — "conhece-te a ti mesmo" — ecoasse por todos os tempos gregos e encontrasse sua total prática na antiguidade tardia, mantendo suas diferenças pertinentes. No entanto, a lição foi bem absorvida: nenhuma vida vale ser vivida se não for, a todo instante, examinada. Aqui o ato sexual é praticado e avaliado na sua relação constante com a própria conduta, pois todo cuidado é importante e necessário. Na medicina greco-romana, o regime dos aphrodisia (dos prazeres, dos amores) foi apresentado como "a forma de uma natureza presente para o pensamento, sua verdade habitando a conduta como sua constante prescrição" (FOUCAULT, 1985, p. 145). Assim, em comparação com os temas preocupantes da ética sexual grega clássica (Dietética, Econômica e Erótica), temos mudanças com a estética da existência cada vez mais dominada pelo cuidado de si. Na problematização da saúde, a mudança deu-se através da viva atenção (que se seguia por uma inquietação intensa) à relação entre o ato sexual e o corpo e suas "consequências perturbadoras"; na problematização do casamento, somada à relação com a mulher, deu-se ao ver surgir uma valorização cada vez mais forte do vínculo 
conjugal, sendo esta justificada não só mais pela questão do status, mas pela natureza de uma relação recíproca; por fim, na problematização do ato com os rapazes, a necessidade de abstinência passa a ser vista menos como forma de amor de alto valor espiritual e mais como imperfeição na relação amorosa (Cf. 1985, pp. 233234).

Mas toda esta mudança, da arte de viver para a arte de si - esta não deixando de se mesclar àquela —, e em seguida para uma arte de confissão, foram acompanhadas por "técnicas" que também mudaram de época em época ${ }^{3}$. A todo processo de subjetivação, em uma determinada cultura, segue-se determinadas "práticas", que tomam formas variadas de acordo com o seu direcionamento na história. Estas "práticas de si" (abstinência, exame de consciência, a prática da escrita, a interpretação dos sonhos, etc.) são

procedimentos [...] que são propostos ou prescritos aos indivíduos para fixar sua identidade, mantê-la ou transformá-la em função de certos fins, e isto graças às relações de governo de si sobre si ou de conhecimento de si para si (FOUCAULT, 1994a, p. 213).

Requerimento de toda uma asckesis, de todo um conjunto de práticas muito forte na "cultura de si". Por mais diferentes que sejam, tanto no fazer como no propósito que estabeleçam, há um objetivo comum entre elas, que se caracteriza pelo princípio de conversão a si (ad se convertere). Neste princípio encontramos a ideia de todo um movimento de pensamento, de existência, onde o indivíduo se volta sobre si próprio e tira disso um grande número de relações consigo. Vemos, então, para onde tais práticas direcionavam os gregos: uma estilização cada vez mais completa da existência em todas as suas ações éticas provocando um efeito de conversão total. A vida toma outra forma diante de si mesma.

Essa definição e esse princípio não impediram Foucault de receber críticas de um dos mais renomados helenistas, Pierre Hadot, que por sinal o ajudou a mergulhar nesse mundo grego. Ele esclarece o que lhe incomoda:

\footnotetext{
Não gosto da expressão "práticas de si”, que entraram em voga graças a Foucault, e muito menos da expressão "escritas de si". O que se pratica não é o "si", e tampouco é o "si" que é escrito. Praticam-se exercícios para transformar o eu, e escrevem-se frases para influenciar o eu. Entre parênteses, esse é um exemplo adicional da impropriedade do jargão filosófico contemporâneo $(2016$, p. 122).
}

Vemos que o foco delimitador e decisivo, apesar da expressão, não é o "si", mas o eu a ser modelado e transformado radicalmente. Por sua vez, isso não significa que a conversão deixe de ser a base prática de trabalho desse eu. E isso também não significa os questionamentos que tanto rondaram esse processo de estilização: estilizar a vida, tendo como base relações consigo, não foi o estabelecimento de uma

\footnotetext{
${ }^{3}$ Foucault não deixa de identificar, em seus estudos, esse deslocamento radical provocado pelo Cristianismo. Do poder pastoral às "confissões da carne", vemos todo um sistema de transmutação cultural que se ancora exclusivamente em uma obediência a um sistema de regras. Saímos da busca contínua de uma autonomia como efeito de exercícios espirituais para uma heteronomia marcada pelo sofrimento e angústia ocasionados pelo pecado.
}

CARMO, Miguel Ângelo Oliveira do. Moral, ética e estética da existência em Michel Foucault. Griot : Revista de Filosofia, Amargosa - BA, v.19, n.2, p.300-310, junho, 2019. 
individualidade? Haveria, aqui, um "retorno ao sujeito", identitário e portador de si? Nem a ética grega, na feitura de uma cultura de si, nem Foucault, nos seus estudos dos processos de subjetivação, propuseram isso:

\begin{abstract}
As exigências de austeridade sexual que foram expressas na época imperial não parecem ter sido a manifestação de um individualismo crescente. Seu contexto é antes de tudo caracterizado por um fenômeno de um bem longo alcance histórico, mas que conheceu nesse momento seu apogeu: o desenvolvimento daquilo que se poderia chamar uma 'cultura de si', na qual foram intensificadas e valorizadas as relações de si para consigo (1985, pp. 48-49).
\end{abstract}

Respondendo à questão acima colocada, é mostrado que no decorrer da história temos que distinguir três coisas: a) a atitude individualista, onde se vê o valor absoluto do indivíduo em sua singularidade e o grau de sua independência correlativa a um grupo social ou instituição aos quais pertence; b) a valorização da vida privada, que é a importância reconhecida às relações familiares, às formas de atividade doméstica e aos interesses patrimoniais; c) a intensidade das relações consigo, que são atitudes nas quais o indivíduo toma a si próprio como objeto de conhecimento e campo de ação para transformar-se, corrigir-se, purificar-se e salvarse (Idem, p. 48). Portanto, temos um processo que em nenhum sentido busca um retorno a um sujeito único, fechado em si, pois tal processo não é estático e se diferencia de outras formas próximas da individualidade ou subjetividade; busca-se, sim, uma transformação infinita da vida, um processo dinâmico no qual o sujeito, no uso corajoso da tua razão, critica o seu tempo e a si próprio nesse tempo. Uma atualidade definidora do seu ser e de tudo que o rodeia. "É necessário, eu penso, sempre o trabalho sobre nossos limites, ou seja, um labor paciente que dá forma à impaciência da liberdade" (FOUCAULT, 1994d, p. 578).

O sujeito neste processo está em um trabalho constante sobre si próprio, ele desengancha-se, liberta-se e, a cada momento, se atualiza onde e como vive. Assim, se há um "retorno ao sujeito", temos a convocação de um sujeito cujo modo de ser é histórico e se encontra em uma modalidade determinada por uma ligação a si; procura-se entender a constituição do sujeito ético na direção prática de uma liberdade na qual, por uma luta de resistência às relações de poder e um traçado no uso próprio da razão, dar-se-á a possibilidade de estilização da vida e do que está à sua volta. Para tanto, é preciso compreender o uso da palavra liberdade nem no seu sentido político contratual, que tanto marcou as políticas tradicionais da época moderna, nem em seu sentido metafísico, que se mostra como desejo no inconsciente coletivo das culturas atuais. Fora das totalizações e apresentações de formas universais, das quais as subjetividades são espelhadas, Foucault apresenta-nos duas maneiras de constituição a que somos submetidos: de um lado, caracterizam-se as práticas de assujeitamento, nas quais toda desistência a uma libertação da vida ganha vigor e morada - aqui, seja por imposições morais, sociais ou políticas, vamos seguindo o escopo de uma verdade tornada evidência; do outro lado, a construção do sujeito pode dar-se por atitudes de libertação, resistentes, criativas, abertas e sem filiações com dominações empreendidas até o momento (1994h, p. 733). É a esta segunda prática que se identifica seu modo de subjetivação, seu 
contágio intransigente e insubordinado diante das estratégias silenciosas de sequestro à vida.

\section{Apontando para algum lugar}

Pensar a moral, a ética e a estética da existência em Foucault e a partir deste nos força a apontar para algum lugar: um novo afeto, novas relações e amizades, questionamentos da cultura vivente, enfim, problematizações da atualidade. A visão de uma moral ancorada ou submetida a uma prática legal instituída e reproduzida socialmente deve nos alertar para o rompimento de limites que ainda estão em voga. A moralidade dos comportamentos e seus códigos morais que expressam suas pesadas leis e valores seculares e impositivos, na nossa contemporaneidade e à luz do que estudamos e aprendemos com a cultura greco-romana, se colocam aptos a problematizações de primeira ordem. Não se trata de comparar modos de vida, o antigo e o atual, mas de reverter o quadro atual com influências pontuais e possibilidades criativas e efetivas na construção do hoje. Não se imita o modo de elaboração subjetiva do grego daquela época, mas pode-se ser influenciado a ponto de propagar práticas inovadoras, quebrando as barreiras morais da tradição. A questão não é moralizar os comportamentos, mas, sendo morais, como liberalizá-los de uma política jurídico-social que domina há séculos.

A ética proposta e diferenciada de certa moral pode ser um caminho positivo. Se o indivíduo deve constituir-se como sujeito moral de suas próprias ações, se se impõe uma relação a si que engrandeça suas práticas e fortaleça seu modo de vida diante da própria vida, é preciso também considerar o real sentido de tal tarefa. Distingue-se essa ética da moral não para afastar essa por completo, mas para aproximá-la de um trabalho em torno das suas ações, ações que diante de si mesmas devem ser a mais ética possível. Sai-se do âmbito limitador da moral para uma abertura ética que embaralha, nas subjetividades, as relações entre teoria e prática. Thomas Bénatouil nos esclarece o uso preciso de uma ética de si nos gregos, percebido pelas análises foucaultianas:

Para Foucault, então, a subjetivação que implica a ética de si helenísticoromana, não tem por princípio o descobrimento de formas específicas do eu, senão uma revisão das relações entre teoria e prática que permite que os saberes e as verdades não reflexivas afetem em profundidade o modo em que se pensa, trabalha sobre si e atua quem as possui (2004, pp. 36-37).

Este processo nos libera das amarras identitárias que nos encapsulam e impedem uma melhor relação entre moral e ética, ou melhor, outra relação. Talvez essa outra relação possa ser encontrada como efeito em uma estética da existência, tão bem disseminada por Nietzsche na sua luta contra a cultura do ressentimento e da impotência. Rosa Dias define bem a estética comparável entre o pensador alemão e o francês, quando expurga o sujeito das metafísicas do mesmo: "O grande inventorexperimentador de si mesmo é o sujeito sem identidade real ou ideal” (2011, p. 128). O objetivo dos gregos, com as "práticas de si", na cultura de si, teve como efeito a fuga de toda fixação da identidade e a determinação de um traçado, acontecimentalmente, corrigível e transformativo. Modelagem transitiva das 
relações consigo que expande nossa liberdade definindo-a na identidade do que fazemos e pensamos com aquilo que somos. A estética da existência proposta por Foucault perpassa essa responsabilidade, essa autonomia crítica naquilo que nos define e que transborda nessa cultura grega.

Vemos que a abordagem de tais conceitos tem apontado para a nossa atualidade contemporânea, onde a "atitude de modernidade", "uma maneira de pensar e sentir, de agir e de se conduzir que, ao mesmo tempo, marca um pertencimento e se apresenta como uma tarefa" (1994d, p. 568), faz-se presente no uso estético da liberdade, da vida. Foi extamente esta semelhança com a moral grega que levou Foucault a se interessar por processos de subjetivação na Antiguidade e a tentar ver proximidades a serem não imitadas nem aproveitadas, mas problematizadas diante do que tendemos a ser quando emparelhados com a regra e a lei:

\footnotetext{
Se me interesso pela Antiguidade, é que, por uma série de razões, a ideia de uma moral como obediência a um código de regras está em vias de, agora, desaparecer - já desapareceu. E a esta ausência de moral, deve responder uma busca que é aquela de uma estética da existência (FOUCAULT, 1994h, p. 732).
}

Uma ausência de moral que nos permitiria, nesta época, a busca de um estilo, de uma mudança, de uma vivência mais livre. Esta vivência se expressa em uma atitude ético-política firme e constante perante a atualidade do indivíduo nas relações sociais; é preciso, aos nos encontrarmos dentro desta posição, tomar consciência da relação entre o poder e a resistência ao mesmo e tirar daí suas consequências mais promissoras. Onde existem relações de poder, há resistência, mas esta não pode ser um simples "não", pois "Dizer não constitui a forma mínima de resistência, (...) É preciso dizer não e fazer deste uma forma de resistência decisiva" (FOUCAULT, 1994j, p. 741). A posição necessária à luta do indivíduo, antes de ser uma moral (no sentido mais prático da palavra), deverá ser ética e estética, e é aqui que a relação conceitual colocada acima ganha seu uso máximo.

Constituir a si próprio, independente dos princípios utilizados (a temperança, no período clássico grego ou o cuidado de si, nos tempos greco-romanos - tudo isso em contraposição aos exercícios codificados do Cristianismo), para só depois acedermos a uma prática moral, na qual os domínios de saber e poder se encontrarão, espera-se, limitados, é nesse trabalho que a relação conceitual entre "moral", "ética" e "estética da existência" pode apontar. E nesse apontar, tem-se em vista todo tempo a liberdade que seja uma liberdade em invenção. 


\section{Referências:}

BÉNATOUÏL, Thomas. Dos usos del estoicismo: Deleuze e Foucault. In: GROS, Frédéric; LÉVY, Carlos. Foucault y la Filosofía Antigua. Trad. de Elena Marengo. Buenos Aires: Nueva Visión, 2004. p. 13-40.

DELEUZE, G. Foucault. Trad. de José Carlos Rodrigues, Editora Veja, 1987.

DIAS, Rosa. Nietzsche, a Vida como Obra de Arte. Rio de Janeiro: Civilização Brasileira, 2011.

FOUCAULT, M. O Uso dos Prazeres. Trad. de Maria T. da Costa Albuquerque, RJ: Ed. Graal, 1984.

FOUCAULT, M. O Cuidado de Si. Trad. de Maria T. da Costa Albuquerque, RJ: Ed. Graal, 1985.

FOUGAULT, M. Subjectivité et Vérité. In: Dits et Écrits IV, Éditions Gallimard, 1994a. p. 213-218.

FOUCAUlT, M. Le sujet et le Pouvoir. In: Dits et Écrits IV, Éditions Gallimard, 1994b. p. 222-243.

FOUCAULT, M. Usage des Plaisirs et Techniques de Soi. In: Dits et Écrits IV, Éditions Gallimard, 1994c. p. 539-561.

FOUCAULT, M. Qu'est-ce que les Lumières? In: Dits et Écrits IV, Éditions Gallimard, 1994d. p. 562-578.

FOUCAULT, M. Ầ Propos de la Généalogie de l'Éthique: un Aperçu du Travail en Cours. in: Dits et Écrits IV, Éditions Gallimard, 1994f. p. 609-631.

FOUCAULT, M. L'Éthique du Souci de Soi Comme Pratique de la Liberté. In: Dits et Écrits IV, Éditions Gallimard, 1994g. p. 708-729.

FOUGAULT, M. Une Esthétique de l'Existence. In: Dits et Écrits IV, Éditions Gallimard, 1994h. p. 730-735.

FOUCAULT, M. Michel Foucault: Une Interview: Sexe, Pouvoir et la Politique de l'Identité" in: Dits et Écrits IV, Éditions Gallimard, 1994j. p. 735-746.

HADOT, Pierre. A Filosofia como Maneira de Viver. Trad. de Lara C. de Malimpensa. São Paulo: É Realizações, 2016.

Autor(a) para correspondência: Miguel Ângelo Oliveira do Carmo, Universidade Federal da Paraíba, Cidade Universitária, 58051-900, João Pessoa - PB, Brasil.mguel@hotmail.com 